\title{
Research on Suspension with Novel Dampers Based on Developed FOA-LQG Control Algorithm
}

\author{
Xiao Ping, ${ }^{1,2}$ Gao Hong, ${ }^{1}$ Lou Jie,, Wang Gang, ${ }^{1,3}$ and Niu Limin ${ }^{4}$ \\ ${ }^{1}$ School of Mechanical and Automotive Engineering, Anhui Polytechnic University, Wuhu, China \\ ${ }^{2}$ School of Mechanical and Automotive Engineering, Hefei University of Technology, Hefei, China \\ ${ }^{3}$ Center for Post-Doctoral Studies, Wuhu Hefeng Clutch Co., Ltd., Wuhu, China \\ ${ }^{4}$ School of Mechanical Engineering, Anhui University of Technology, Maanshan, China
}

Correspondence should be addressed to Xiao Ping; xp1995@mail.hfut.edu.cn

Received 2 June 2016; Accepted 27 December 2016; Published 14 February 2017

Academic Editor: Dane Quinn

Copyright (c) 2017 Xiao Ping et al. This is an open access article distributed under the Creative Commons Attribution License, which permits unrestricted use, distribution, and reproduction in any medium, provided the original work is properly cited.

\begin{abstract}
To enhance working-performance robustness of suspension, a vehicle suspension with permanent-magnet magnetic-valve magnetorheological damper (PMMVMD) was studied. Firstly, mechanical structure of traditional magnetorheological damper (MD) used in vehicle suspensions was redesigned through introducing a permanent magnet and a magnetic valve. Based on theories of electromagnetics and Bingham model, prediction model of damping force was built. On this basis, two-degree-of-freedom vehicle suspension model was established. In addition, fruit fly optimization algorithm- (FOA-) line quadratic Gaussian (LQG) control algorithm suitable for PMMVMD suspensions was designed on the basis of developing normal FOA. Finally, comparison simulation experiments and bench tests were conducted by taking white noise and a sine wave as the road surface input and the results indicated that working performance of PMMVMD suspension based on FOA-LQG control algorithm was good.
\end{abstract}

\section{Introduction}

Because MDs have advantages of easy adjustment and low energy consumption, they are widely applied in vibration damping fields of vehicle suspensions, building, and so on. At present, many scholars focus their research on different sides of MD and have achieved some achievements [1-4]. $\mathrm{Ni}$ et al. conducted experimental identification on a selfinductance MD through computer software [5]. Shah et al. carried out experimental research on performance of magnetorheological fluids based on plate-like iron particles [6]. Caterino studied vibration damping of wind turbine with MDs [7]. Zalewski et al. built a new dynamic model for MDs [8]. Yazid et al. designed a MD with a combination of shear and squeeze modes [9]. Sohn et al. designed a MD with piston bypass hole, which could achieve smaller damping force at lower speed area and bigger damping force at higher damping force [10]. Sun et al. designed an enhancement-type MD with variable stiffness and damping coefficients through two magnetorheological units and one spring [11]. Ito et al. developed a novel rotary MD and conducted simulation and bench tests on the damper [12]. At present, in spite of these research achievements on MDs, some tricky problems still remain unsettled, which leaves much room for further study. For instance, when vehicles with MDs stop moving for a moment, sedimentation of magnetorheological fluid in MDs will happen; that is, magnetic particles will fall and hard lump will take shape because of losing magnetic field. Therefore, the hard lump will block the annular gap of MD, so suspensions will lose vibration damping ability when vehicles start to work again. In order to solve this problem, this paper proposes a new MD with a permanent magnet and a magnetic valve; the permanent magnet can provide stable magnet field for the annular gap of MDs; the magnetic valve can adjust the damping force. Hence, sedimentation problem of magnetorheological fluid in MDs can be solved 

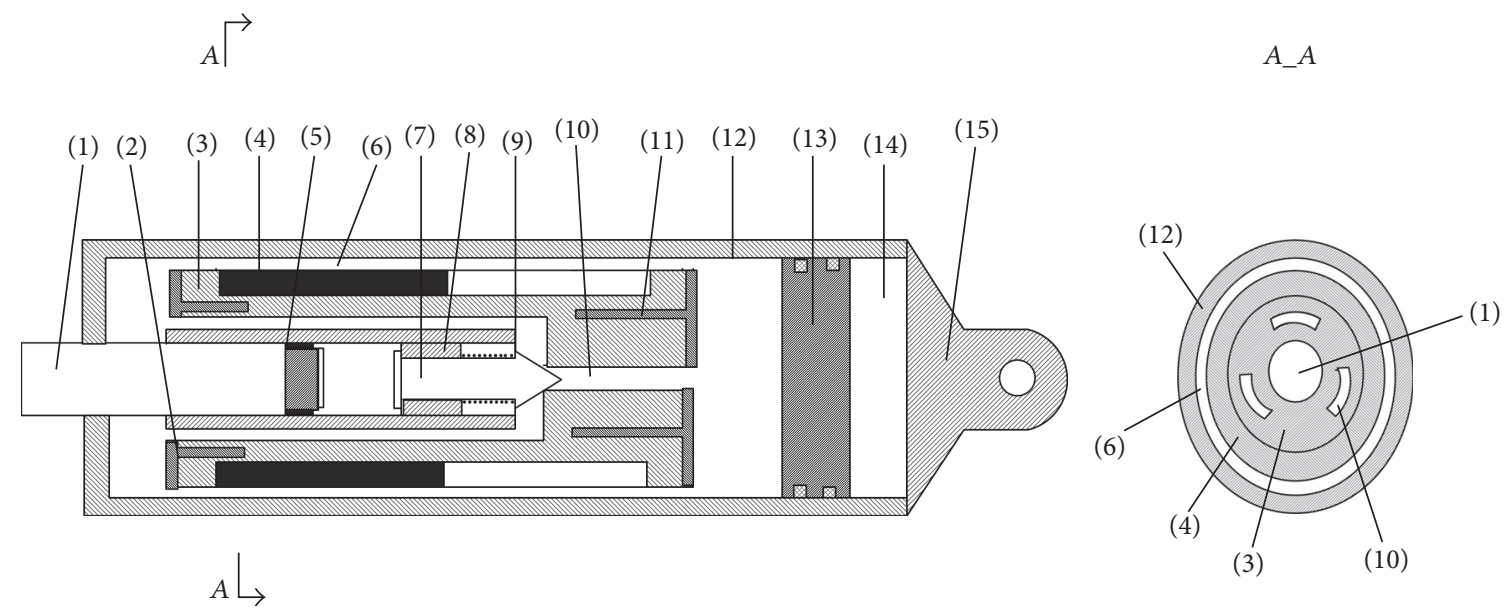

FIGURE 1: Mechanical structure: (1) piston rod; (2) stainless-steel magnetoresistive plate; (3) I-section piston head; (4) circular permanent magnet; (5) magnet coil; (6) annular gap; (7) valve plug; (8) screw tube; (9) back spring; (10) magnetic-valve pipe; (11) stainless-steel magnetoresistive plate; (12) cylinder barrel; (13) floating piston; (14) compensation chamber; (15) ear loop.

successfully. On the basis of the above principle, a new PMMVMD for vehicle suspension is designed. Moreover, the vehicle suspension system is a controlling system with high cooperation of hardware and software, so highly effective controlling algorithm must be equipped to it [13-15]. LQG is regarded as an ideal control algorithm for suspension system because it can enhance its comprehensive performance through taking multiple control objectives into consideration simultaneously [16]. However, optimizing weighted factors for LQG controllers still remains a tricky problem. Thus, FOA with superb searching ability and rapid optimization speed is introduced to optimize LQG controllers in this paper [17-20]. Meanwhile, in order to enhance optimization efficiency and accuracy, homogeneousdistribution operation of fruit fly groups and group-radiusdecrease-with-optimization-generation-increase operation are introduced to normal FOA so that a novel FOA-LQG control algorithm suitable for PMMVMD suspension is designed.

Based on the above work, two simulation experiments are conducted by taking white noise road surface and sine wave road surface as input and bench tests are carried out, as well.

\section{Modeling of PMMVMD Suspension}

2.1. Modeling of PMMVMD. The mechanical structure of the researched PMMVMD is shown in Figure 1. A circular permanent magnet is installed in the recess of I-section piston head. Annular gap forms between outer surface of piston head and inner side of cylinder barrel. There is a magnet coil, a valve plug, a back spring, a screw tube, and magnetic-valve pipes in the piston head, which make up the magnet valve. If the coil is input with current of certain strength, magnetic valve will open to a corresponding degree. The stronger the input current is, the higher the open degree is. Some liquid not creating damping force flows through magnetic valve, while the rest of creating damping force flows through annular gap. In this way, damping force can be regulated via adjusting the open degree of magnetic valve. Magnetic circuit diagram is shown in Figure 2, which indicates that magnetic line of force is in a circle: $A 1 \rightarrow A 2 \rightarrow A 3 \rightarrow A 4 \rightarrow A 3 \rightarrow A 2$ $\rightarrow$ A1.

According to the working principle of PMMVMD, shear yield stress of critical point $\tau_{y}$ can be calculated by the following [21-24]:

$$
\tau_{y}=\alpha^{\prime}\left(\frac{F^{\prime \prime}}{k_{f}\left(R^{\prime}+R_{m 1}+2 R_{m 2}+2 R_{m 3}+R_{m 4}\right)\left(\pi r_{2}^{2}+2 \pi r_{2}\left(r_{3}-r_{2}\right)\right)}\right)^{k},
$$

where $\alpha^{\prime}, k$ are parameters related to magnetorheological liquid; $R_{m 1}, R_{m 2}, R_{m 3}, R_{m 4}$ are magnetic resistance at $A_{1}$, $A_{2}, A_{3}, A_{4}$, respectively; $F^{\prime \prime}, R^{\prime}$ are magnetic potential of permanent magnet and magnetic resistance; $k_{f}$ is magnetic leakage factor; $r_{2}, r_{3}$ are shown in Figure 2.

Given that total flow rate of magnetorheological liquid in the process of piston moving is $Q$, which can be calculated by

$$
Q=A_{p} \cdot v,
$$

where $A_{p}$ is sectional area of piston head and $v$ is relative velocity between piston and cylinder barrel, then, the liquid $Q_{2}$ flowing through valve pipes can be calculated by the following [25]:

$$
Q_{2}=\pi^{2}\left(r^{\prime \prime}-\frac{\sqrt[3]{N^{\prime 2} I^{\prime 2} \mu_{0} S^{\prime} / 2 k^{\prime}} r^{\prime}}{h^{\prime}}\right)^{2} v
$$




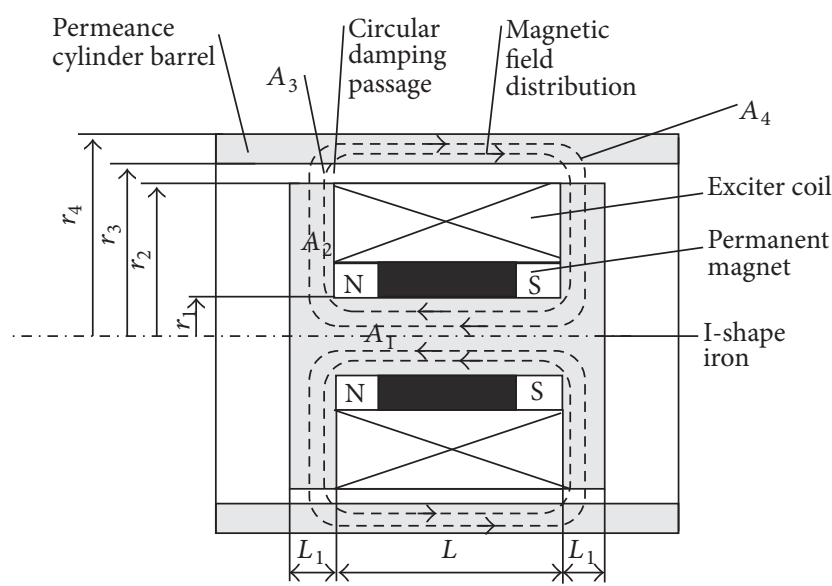

FIGURE 2: Diagram of magnetic circuit.

where $I^{\prime}$ is input current, $N^{\prime}$ is turn number, $\mu_{0}$ is magnetic permeability, $s^{\prime}$ is area of valve plug's left end, and $k^{\prime}$ is stiffness coefficient of back spring; $h^{\prime}, r^{\prime}$ are height and basal diameter of the cone (the shape of right end of valve plug is conical); $r^{\prime \prime}$ is radius of right valve pipe.

Through putting parameters of designed novel damper into Bingham model [26-28], damping force $F_{d}$ of PMMVMD can be expressed by

$$
\begin{aligned}
F_{d} & =\left(\frac{24 \eta\left(Q-Q_{2}\right)^{2}\left(L+2 L_{1}\right)}{\pi\left(r_{3}+r_{2}\right) v\left(r_{3}-r_{2}\right)^{3}}\right. \\
& \left.+\frac{2 \eta \pi\left(r_{3}+r_{2}\right)\left(L+2 L_{1}\right) v}{\left(r_{3}-r_{2}\right)}\right) \\
& +\left(\frac{4\left(L+2 L_{1}\right)\left(Q-Q_{2}\right)}{\eta v}\right. \\
& \left.+2 \pi\left(r_{3}+r_{2}\right)\left(L+2 L_{1}\right)\right) \tau_{y} \cdot \operatorname{sgn}(v)+f,
\end{aligned}
$$

where $F_{d}$ is damping force of MD; $\eta$ is plastic viscosity of liquid; $f$ is offset force; $L_{1}, L$ are shown in Figure 2 .

2.2. Modeling of PMMVMD Suspension. Figure 3 displays the physical model of a researched quarter suspension, according to which its mathematic model can be expressed by the following [29]:

$$
\begin{array}{r}
m_{s} x_{s}^{\prime \prime}+k_{s}\left(x_{s}-x_{t}\right)+F_{d}=0, \\
m_{t} x_{t}^{\prime \prime}+k_{t}\left(x_{t}-x_{r}\right)-k_{s}\left(x_{s}-x_{t}\right)-F_{d}=0,
\end{array}
$$

where $m_{s}, m_{t}$ are vehicle sprung mass and unsprung mass; $x_{s}, x_{t}, x_{r}$ are displacement of sprung mass, displacement of unsprung mass, disturbance input from the road, respectively; $k_{s}, k_{t}$ are stiffness coefficient of suspension spring and tyre.

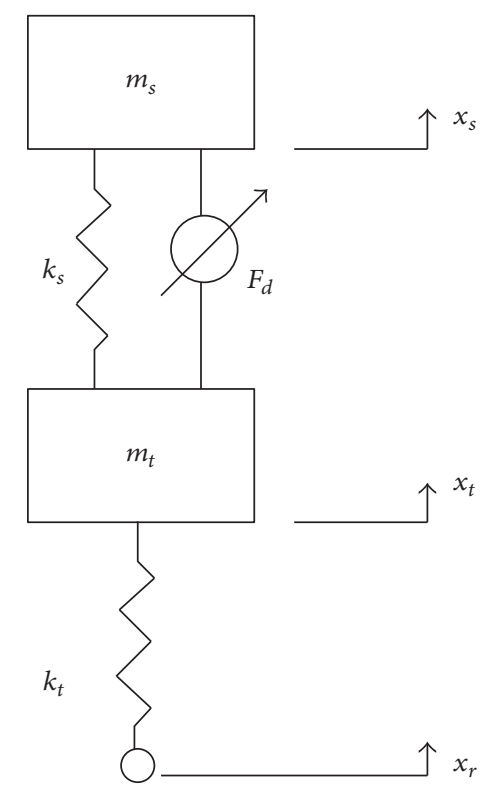

FIgURE 3: Physical model of a quarter suspension.

\section{Design of FOA-LQG Control Algorithm}

3.1. The Development of FOA. In the process of optimization through FOA, the number of fruit fly groups and group radius of each fruit fly have a great impact on optimization speed and accuracy. Therefore, this paper intends to optimize the number of fruit groups and group radius of each fruit fly in optimization in the following way.

3.1.1. Homogeneous-Distribution Operation of Fruit Fly Group. In optimization of normal FOA, only a fruit fly group consisting of different fruit fly number is employed and all fruit flies conduct optimization around the group centre [3032]. Therefore, there is only a single group centre in the process of optimization. Only when the group centre is near the optimal value, there is possibility for individual fruit fly in the group to find the optimal solution. The original position of group centre is assigned by computers with randomness. Therefore, the original position of FOA with only one fruit fly group has a great impact on its convergence speed. In order to enhance performance of FOA, homogeneousdistribution operation of fruit fly group is proposed in this paper; that is, in FOA optimizing process, multiple small fruit fly groups are employed to conduct optimization in the solution space simultaneously. Moreover, the solution space is divided evenly into several subspaces with each one containing a small fruit fly group. Thus, the centre positions of fruit fly groups can reach the optimal value easily because every subspace has a searching simultaneously small fruit fly group in the whole solution space. In this way, optimization speed can be greatly quickened.

Homogeneous-distribution operation of fruit fly group is conducted in the following way: Firstly, let us suppose that optimizing space is $\left[\alpha_{1}, \alpha_{2}, \ldots, \alpha_{n}\right]$; that is, optimal solution of the would-be optimized problem lies in the space determined 
by $\alpha_{1}, \alpha_{2}, \ldots, \alpha_{n}$. Space $\left[\alpha_{1}, \alpha_{2}, \ldots, \alpha_{n}\right]$ can be divided into $n$ subspaces $\Omega_{i^{\prime}}^{\prime \prime}\left(i^{\prime}=1,2, \ldots, n\right)$

$$
\Omega_{i^{\prime}}^{\prime \prime}=\sum_{i^{\prime}=1}^{n}\left[\alpha_{i^{\prime}}, \alpha_{2}, \ldots, \alpha_{n}\right]
$$

where $\left|\alpha_{i^{\prime}}\right|=(1 / n)\left|\alpha_{1}\right|$.

Then, create $n$ fruit fly groups $F_{i^{\prime}}$ randomly and each group includes several fruit flies. In the optimization process, each fruit fly group $F_{i^{\prime}}$ is assigned to a subspace $\Omega_{i^{\prime}}^{\prime \prime}$ so that $n$ fruit fly groups can be distributed homogeneously into optimal solution space $\left[\alpha_{1}, \alpha_{2}, \ldots, \alpha_{n}\right]$. Thus, global optimal solution can be achieved after iteration optimization.

3.1.2. Group-Radius-Decrease-with-Increase-of-OptimizationGeneration Operation. FOA has some such advantages as great versatility, rapid searching speed, high efficiency, and so on. But in normal FOA optimization process, group radius of each fruit fly is a constant value, which has a bad impact on optimizing of fruit fly groups, because if the radius of fruit group is bigger, fruit fly groups tend to skip optimal solution, with the global optimizing speed being reduced; if the radius of fruit groups is smaller, the local searching ability will be enhanced, but it is easy for the algorithm to fall into local optimum, or the convergence speed will be reduced. Therefore, in this paper, the group radius will decease with the increase of iteration generation according to

$$
R_{i}^{\prime \prime}=R_{0}^{\prime \prime}+\frac{\tau_{1}}{\sigma_{1}^{i}}
$$

where $R_{i}^{\prime \prime}$ is group radius of $i$ th iteration; $R_{0}^{\prime \prime}, \tau_{1}, \sigma_{1}$ are parameters of the algorithm, $\tau_{1}>0, \sigma_{1}>1$.

Thus, in the beginning of optimizing, the novel algorithm has great global searching ability to find the optimal area soon; in the ending period, it has great local searching ability to find the extremal point of optimal area.

\subsection{Simulation Experiments of Verifying Optimization Effects.} In order to verify effects of developed FOA with two operations mentioned above, 6 standard tested functions $\left(f_{1} \sim f_{6}\right)$ are employed to carry out simulation experiments (these functions are from literature [33]). The novel FOA is employed to optimize minimum values of the 6 functions, with their function names and features listed in Table 1. In simulation, parameters of FOA are set as follows: number of fruit fly groups is 10 , each fruit fly group has 10 fruit flies, iteration number is $200, R_{0}^{\prime \prime}$ is $0.05, \tau$ is 2 , and $\sigma$ is 1.5 . To avoid accidental error, simulation experiments on normal FOA and developed FOA are conducted for 20 times, respectively, and the simulation results are presented in Figures 4(a)4(f). Figures 4(a)-4(f) indicate that convergence speed of developed FOA is faster than that of normal FOA and its optimizing accuracy is higher than that of normal FOA. Therefore, the following conclusion can be arrived at that developed FOA has greater searching ability and better effects than normal FOA.
TABLE 1: Tested functions and their minimum values.

\begin{tabular}{lccc}
\hline & Tested functions & Search scope & Minimum value \\
\hline$f_{1}$ & Becker and Lago & {$[-10,10]$} & 25 \\
$f_{2}$ & Modified Rosenbrock & {$[-5,5]$} & 0 \\
$f_{3}$ & Schaffer $\mathrm{F}_{6}$ & {$[-10,10]$} & 0 \\
$f_{4}$ & BR-Branin & {$[-5,10]$} & 0.398 \\
$f_{5}$ & RA-Rastrigin & {$[-1,1]$} & -2 \\
$f_{6}$ & Rosenbrock & {$[-2.048,2.048]$} & 0 \\
\hline
\end{tabular}

3.3. Design of FOA-LQG Control Algorithm. The novel FOA with homogeneous-distribution operation of fruit fly group and group-radius-decrease-with-increase-of-optimizationgeneration operation is combined with LQG controller so that FOA-LQG control algorithm suitable for PMMVMD suspensions can be designed. The essence of FOA-LQG control algorithm is to optimize 3 weighted factors $q_{1}, q_{2}$, $q_{3}$ of LQG controller by developed FOA and to control PMMVMD suspension by the optimized LQG controller. The principle of controlling PMMVMD suspension by FOA-LQG is shown in Figure 5. 3 weighted factors $q_{1}, q_{2}$, $q_{3}$ of LQG controller are regarded as food of fruit flies and sensitive olfaction of fruit flies is used to search for the food. At the same time, the third and fourth steps of normal FOA are combined and LQG controllers represented by point positions are employed to calculate smell density of the fruit flies. In this way, the specific parameters of FOA can be combined with fruit fly position points directly, which simplifies optimizing steps and enhances efficiency to a large extent.

The workflow of developed FOA is described as follows.

Step 1. Initialize position $\left(X_{j^{\prime}}^{1}, X_{j^{\prime}}^{2}, X_{j^{\prime}}^{3}\right)$ for $m$ fruit fly groups (where $j^{\prime}=1,2, \ldots, m$ ) according to homogeneousdistribution operation of fruit fly group mentioned in Section 3.1.

Step 2. Assign random $\eta$ of searching food by smell to each fruit fly and renew group radius $R_{i}^{\prime \prime}$ according to (7). Position coordinates of fruit groups after $i$ th iteration can be expressed by

$$
\begin{aligned}
& X_{m, i}^{1}=X_{m, i-1}^{1}+R_{i}^{\prime \prime}\left(\eta_{i}-0.5\right), \\
& X_{m, i}^{2}=X_{m, i-1}^{2}+R_{i}^{\prime \prime}\left(\eta_{i}-0.5\right), \\
& X_{m, i}^{3}=X_{m, i-1}^{3}+R_{i}^{\prime \prime}\left(\eta_{i}-0.5\right),
\end{aligned}
$$

where $\left(X_{m, i}^{1}, X_{m, i}^{2}, X_{m, i}^{3}\right)$ is position coordinates of $m$ th fruit group after $i$ th iteration.

Step 3. Calculate directly smell density of individual fruit fly position based on spatial coordinate parameters.

The smell density of designed FOA-LQG controller is represented by control-effect fitness function of LQG controller corresponding to the fruit fly position in this paper. Based on the above suspension model, the target performance index $J$ 


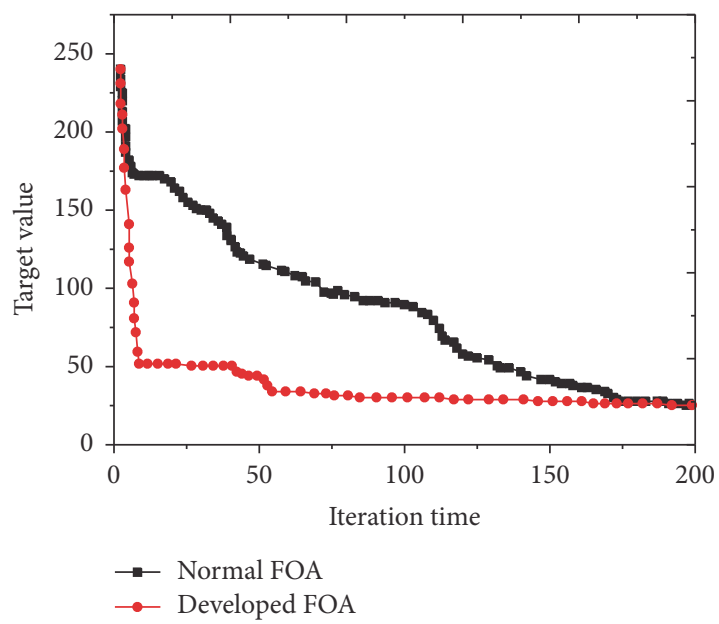

(a)

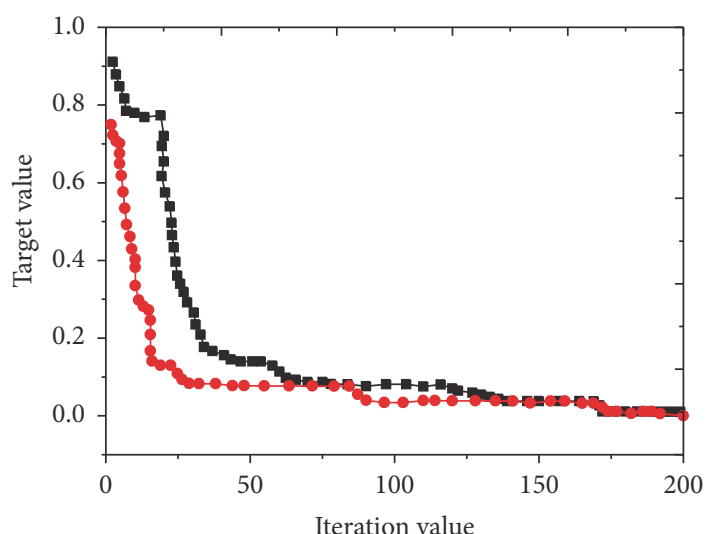

$\rightarrow$ Normal FOA

- - Developed FOA

(c)

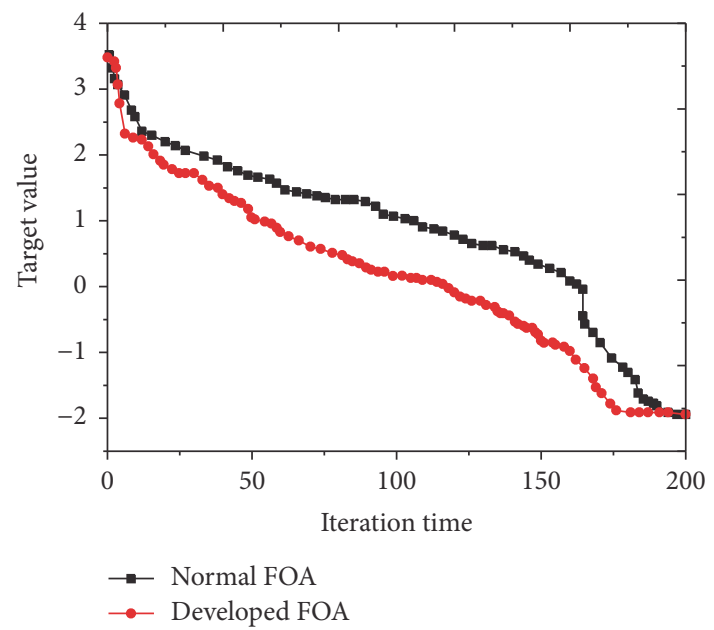

(e)

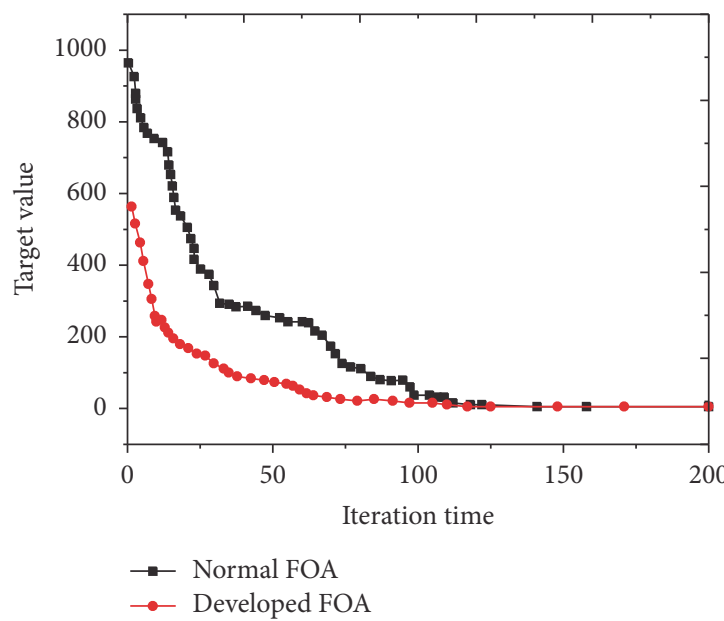

(b)

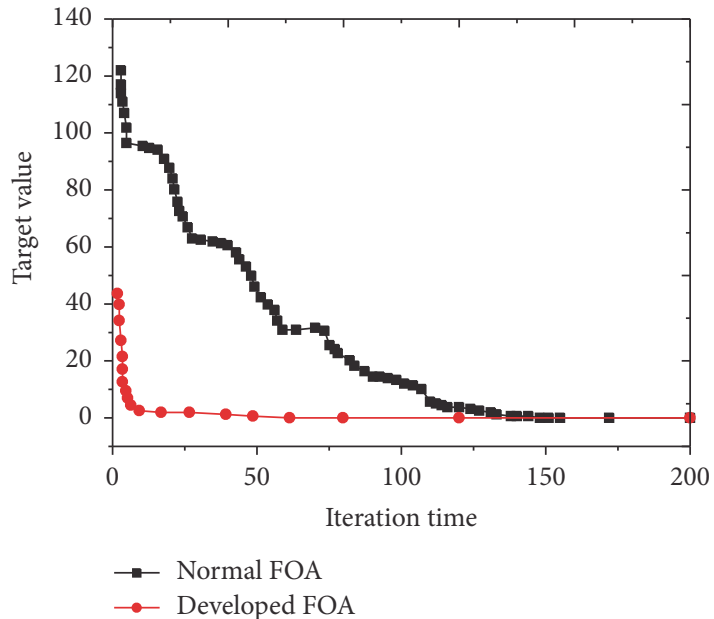

(d)

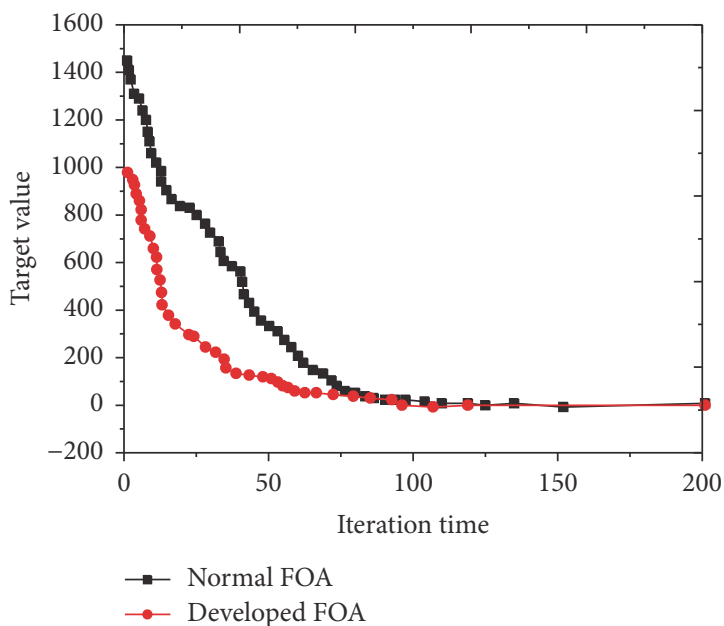

(f)

FIGURE 4: Algorithm comparison of optimizing $f_{1} \sim f_{6}$ : (a) algorithm comparison of optimizing tested function $f_{1}$; (b) algorithm comparison of optimizing tested function $f_{2}$; (c) algorithm comparison of optimizing tested function $f_{3}$; (d) algorithm comparison of optimizing tested function $f_{4}$; (e) algorithm comparison of optimizing tested function $f_{5}$; (f) algorithm comparison of optimizing tested function $f_{6}$. 


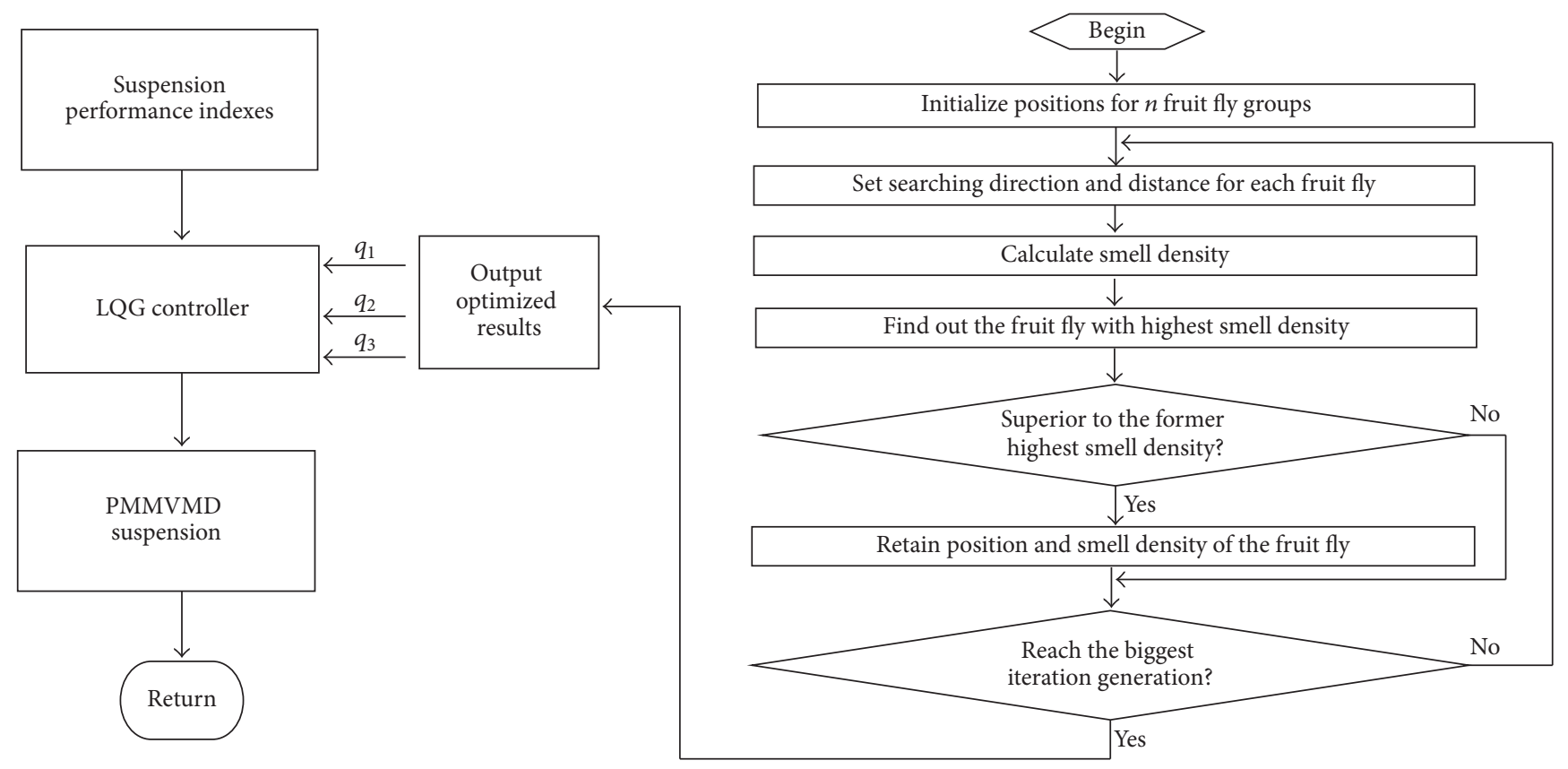

FIGURE 5: Principle of controlling PMMVMD suspension by FOA-LQG.

TABLE 2: RMS value of simulation with B road input.

\begin{tabular}{lcccc}
\hline RMS value & Passive suspension & Sky-hook damping control & Fuzzy control & FOA-LQG control \\
\hline VMCV acceleration/m·s $\mathrm{s}^{-2}$ & 0.469 & 0.427 & 0.347 & 0.325 \\
Suspension dynamic deflection/m & 0.014 & 0.012 & 0.011 & 0.009 \\
Tyre dynamic load/N & 625.329 & 583.28 & 548.67 & 522.75 \\
\hline
\end{tabular}

of LQG is employed as fitness function of FOA, which can be expressed by

$$
\begin{aligned}
J= & \lim _{T \rightarrow \infty} \frac{1}{T} \\
& \cdot \int_{0}^{T}\left[q_{1}\left(x_{s}-x_{t}\right)^{2}+q_{2}\left(x_{t}-x_{r}\right)^{2}+q_{3} x_{s}{ }^{2}\right] d t .
\end{aligned}
$$

Step 4. Find the individual fruit fly with the highest smell density in each group (calculate the maximum value of best smell bestsmell ${ }_{m}^{i}$ and its corresponding number).

Step 5. Retain the maximum value of bestsmell ${ }_{m}^{i}$ and its corresponding number in each group. Then, every individual fruit fly in this group flies to this position by its vision.

Step 6. Conduct iteration optimization and the optimum position obtained in Step 5 becomes the original position of next iteration optimization. Judge whether the smell density is higher than the present one. If the answer is yes, go to execute Step 5; otherwise go to execute Steps 2-4 again.

\section{Experiments}

In order to verify the working performance of designed PMMVMD suspension based on FOA-LQG control algorithm, a vehicle is employed to carry out simulation experiments (experiments of verifying algorithms and experiments of verifying suspension system) and bench tests. The main parameters of the simulation vehicle are as follows: $m_{s}=$ $330 \mathrm{~kg}, m_{t}=50 \mathrm{~kg}, k_{s}=20 \mathrm{kN} / \mathrm{m}$, and $k_{t}=210 \mathrm{kN} / \mathrm{m}$.

4.1. Simulation Experiments of Verifying Algorithms. These simulation experiments aim to verify the control effect of PMMVMD suspension based on designed FOA-LQG control algorithm. Meanwhile, simulation curves of PMMVMD suspension controlled by FOA-LQG control algorithm are compared with those of ones controlled by fuzzy control and sky-hook damping control and with those of passive suspension. In this simulation, the input is B road surface with surface roughness $G_{x r}\left(n_{0}\right)=64 \times 10^{-6}$; simulation speed is $u^{\prime}=50 \mathrm{~km} / \mathrm{h}$. The simulation results are shown in Figures 6(a), 6(b), and 6(c). Moreover, root mean square (RMS) values of vehicle mass centre vertical (VMCV) acceleration, suspension dynamic deflection, and tyre dynamic load are calculated and shown in Table 2.

Figures 6(a), 6(b), and 6(c) indicated that peak values of VMCV acceleration, suspension dynamic deflection, and 


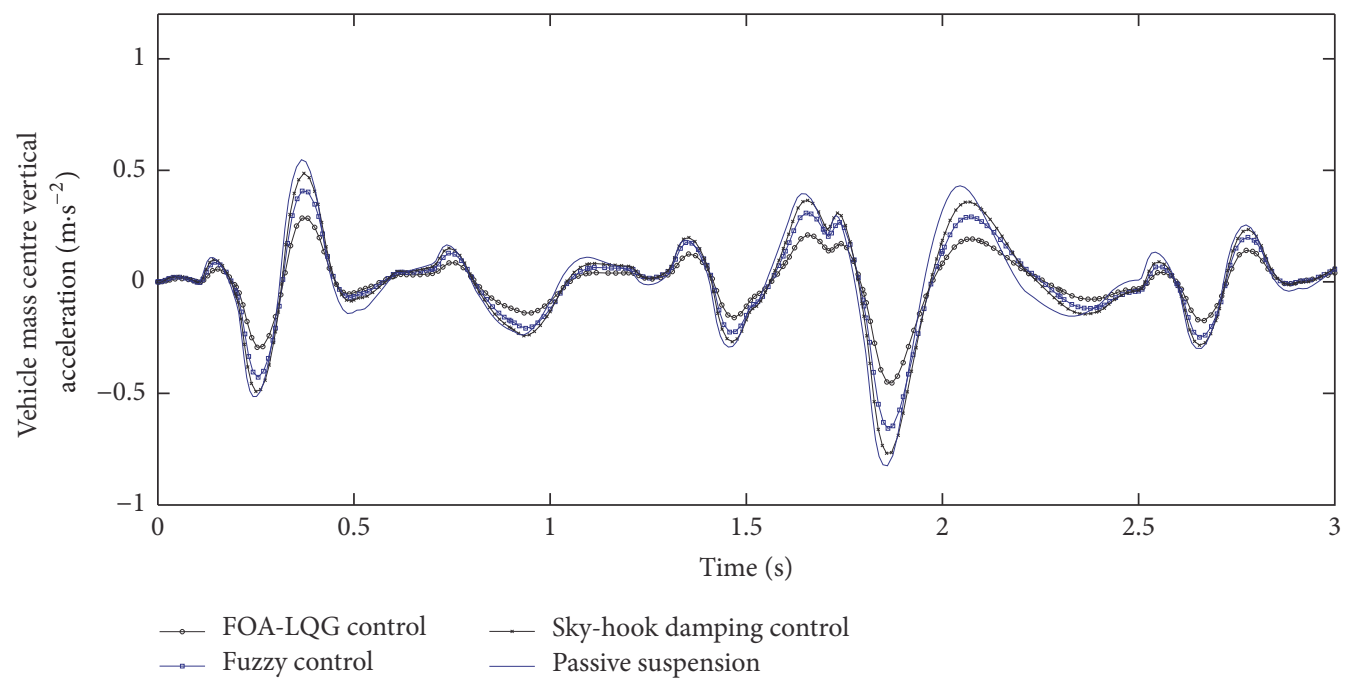

(a)

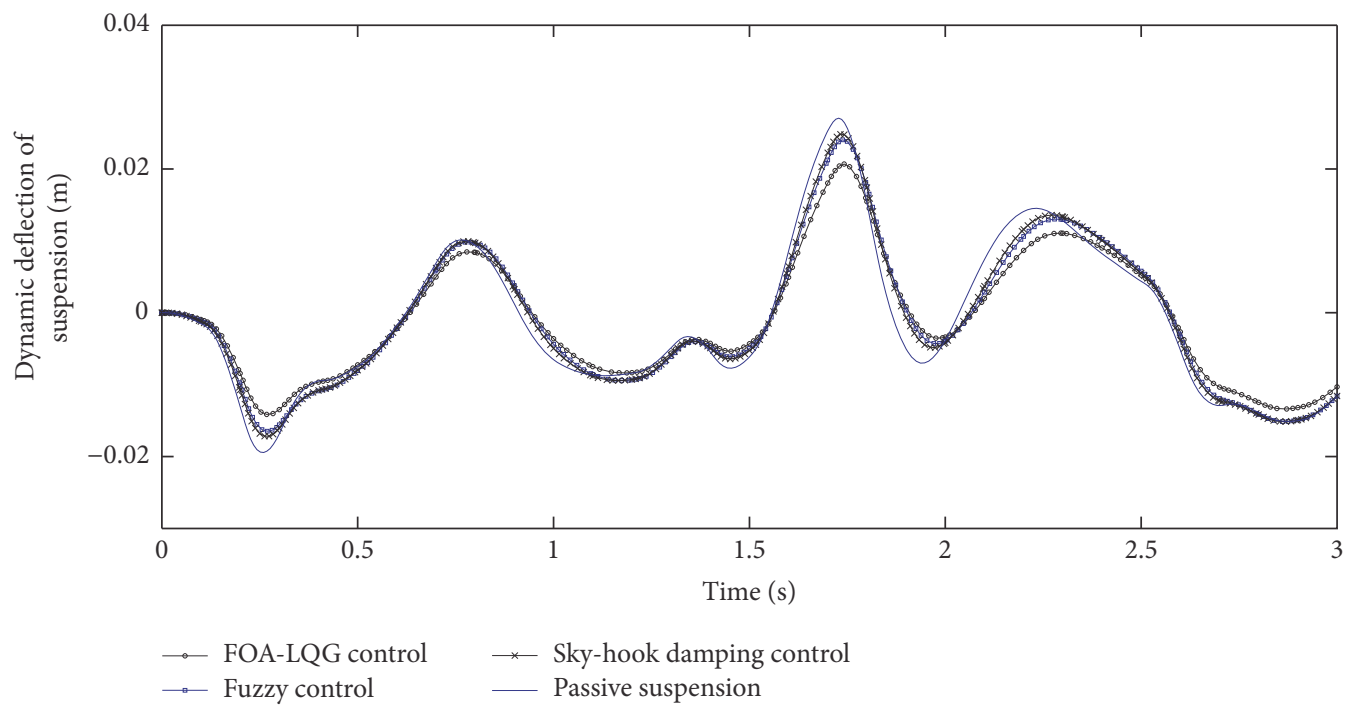

(b)

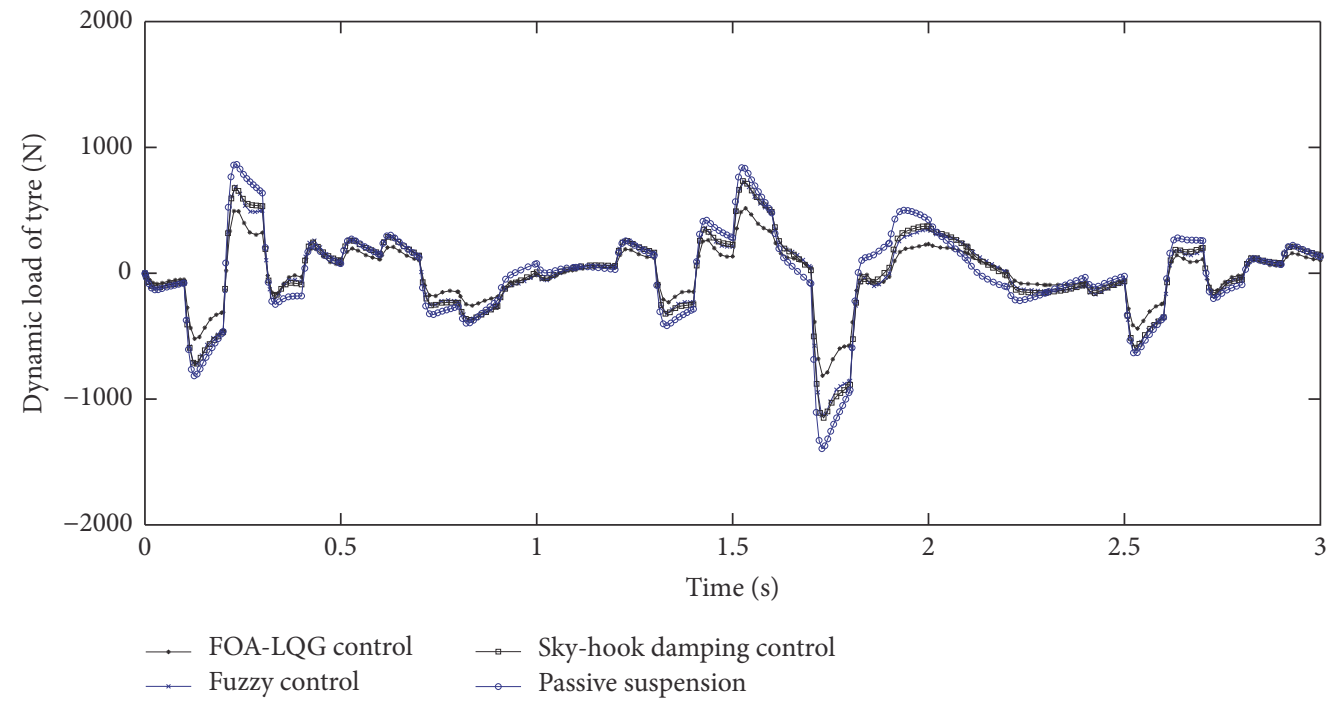

(c)

FIGURE 6: Results of simulation experiments with B road surface input: (a) curve of VMCV acceleration; (b) curve of suspension dynamic deflection; (c) curve of tyre dynamic load. 
TABLE 3: RMS values of simulation with sine wave road input.

\begin{tabular}{lccc}
\hline RMS values & Passive suspension & Normal MD suspension & PMMVMD suspension \\
\hline VMCV acceleration $/ \mathrm{m} \cdot \mathrm{s}^{-2}$ & 2.475 & 1.703 & 1.267 \\
Suspension dynamic deflection $/ \mathrm{m}$ & 0.028 & 0.017 & 0.015 \\
Tyre dynamic load/N & 758.573 & 627.855 & 546.949 \\
\hline
\end{tabular}

tyre dynamic load of vehicle with PMMVMD suspension controlled by FOA-LQG are smaller than those of passive suspension; Table 2 indicates that RMS values of VMCV acceleration, suspension dynamic deflection, and tyre dynamic load of vehicle with PMMVMD suspension controlled by FOA-LQG decrease by $30.7 \%, 35.7 \%$, and $16.4 \%$, respectively, compared with those of passive suspension.

Figures 6(a), 6(b), and 6(c) indicate that peak values of VMCV acceleration, suspension dynamic deflection, and tyre dynamic load of vehicle with PMMVMD suspension controlled by sky-kook damping control, fuzzy control, and FOA-LQG decrease sequentially. Likewise, Table 2 indicates that RMS values of VMCV acceleration, suspension dynamic deflection, and tyre dynamic load controlled by the above 3 control algorithms also decrease sequentially. It can be concluded through the above analysis that vehicles' riding performance, vehicle body posture, and tyre grounding performance are enhanced under the control of FOA-LQG; control effect on PMMVMD suspension of FOA-LQG is better than that of sky-kook damping control and fuzzy control.

4.2. Simulation Experiments of Verifying Suspension Working Performance. These simulation experiments aim to verify the working performance of designed PMMVMD suspension. In the simulations, the results of PMMVMD suspension controlled by FOA-LQG are compared with those of normal MD suspension controlled by FOA-LQG and those of passive suspension. Sine wave road surface is employed as the input and expressed by (10). Simulation results are shown in Figures 7(a), 7(b), and 7(c).

$$
x_{r}=0.05 \times \sin (2 \pi \times 0.97 t)+0.03 \sin (2 \pi \times 0.54 t) .
$$

Figure 7 (a) indicates that compared with those of passive suspension, peak values of VMCV acceleration of PMMVMD suspension and normal MD suspension decrease, which indicates that the two half-active suspensions can enhance vehicle riding performance. Figure 7 (c) indicates that compared with that of passive suspension, tyre dynamic load of PMMVMD suspension and normal MD suspension decreases, which means that the two half-active suspensions can suppress the vibration of tyres and enhance the driving safety. In order to further compare working performance of the two suspensions, simulation results of the two halfactive suspensions and passive suspension are calculated and listed in Table 3 so that quantitative analysis is conducted. Table 3 indicates that compared with those of the vehicle with passive suspension, RMS values of VMCV acceleration, suspension dynamic deflection, and tyre dynamic load of vehicle with normal MD suspension decrease by $31.2 \%, 39.3 \%$, and
$17.2 \%$, respectively; compared with those of the vehicle with normal MD suspension, RMS values of VMCV acceleration, suspension dynamic deflection, and tyre dynamic load of vehicle with PMMVMD suspension decrease by $25.6 \%, 11.7 \%$, and $12.9 \%$, respectively. The above quantitative analysis can lead to the conclusion that the two half-active suspensions can enhance comprehensive performance of vehicles and working performance of PMMVMD suspension is better than that of normal MD suspension.

4.3. Bench Tests. The designed PMMVMD is installed on PA20-Z-20kN electrohydraulic servo suspension testing system produced by Changchun Kexin Co., Ltd. so that quarter vehicle suspension testing system is built, which is shown in Figure 8. In the suspension testing system, vehicle sprung mass and unsprung mass are imitated by mass blocks. A tyre is installed through a clamp on the exciter, which is controlled by electrohydraulic servo system to form road surface excitation acting on the tyre. To collect vibration data, two acceleration pick-up sensors CA-YD-160 are fixed on two cross beams, on which sprung mass and unsprung mass are mounted. Displacement of exciter is measured by W-DC sensor. Suspension vibration data of acceleration pick-up sensors and displacement pick-up sensor is sent to industrial computer, saved, and processed. D2P prototype controller produced by Woodward, Inc. is employed as the PMMVMD suspension controller, which communicates with the industrial computer through CAN bus. Based on vibration state signals from the industrial computer and FOALQG control algorithm, D2P prototype controller calculates controlling electric current of PMMVMD magnetic valve and applies the current to it to optimize vehicle suspension performance. Meanwhile, D2P prototype controller collects control electric current of the magnetic valve through hall current pick-up sensor HBC10ES5 so that closed loop control can form. The signals of vehicle speed and road surface in bench tests are the same with those in simulation experiment in Section 4.2. Testing results are shown in Figures 9(a), 9(b), and $9(\mathrm{c})$.

Figure 9(a) indicates that vibration performance of PMMVMD suspension is good and the biggest acceleration is lower than $0.675 \mathrm{~m} \cdot \mathrm{s}^{-2}$; RMS value of acceleration is $1.242 \mathrm{~m} \cdot \mathrm{s}^{-2}$; the two above results nearly agree with those of simulation results. Meanwhile, comparison of Figures 7(a) and 9(a) indicates that bench test results conform to simulation results, which proves that designed PMMVMD suspension based on FOA-LQG control algorithm can enhance the riding performance of vehicles. Meanwhile, comparison of Figures 7(b) and 7(c) and Figures 9(b) and 9(c) indicates consistency between simulation results and bench test results 


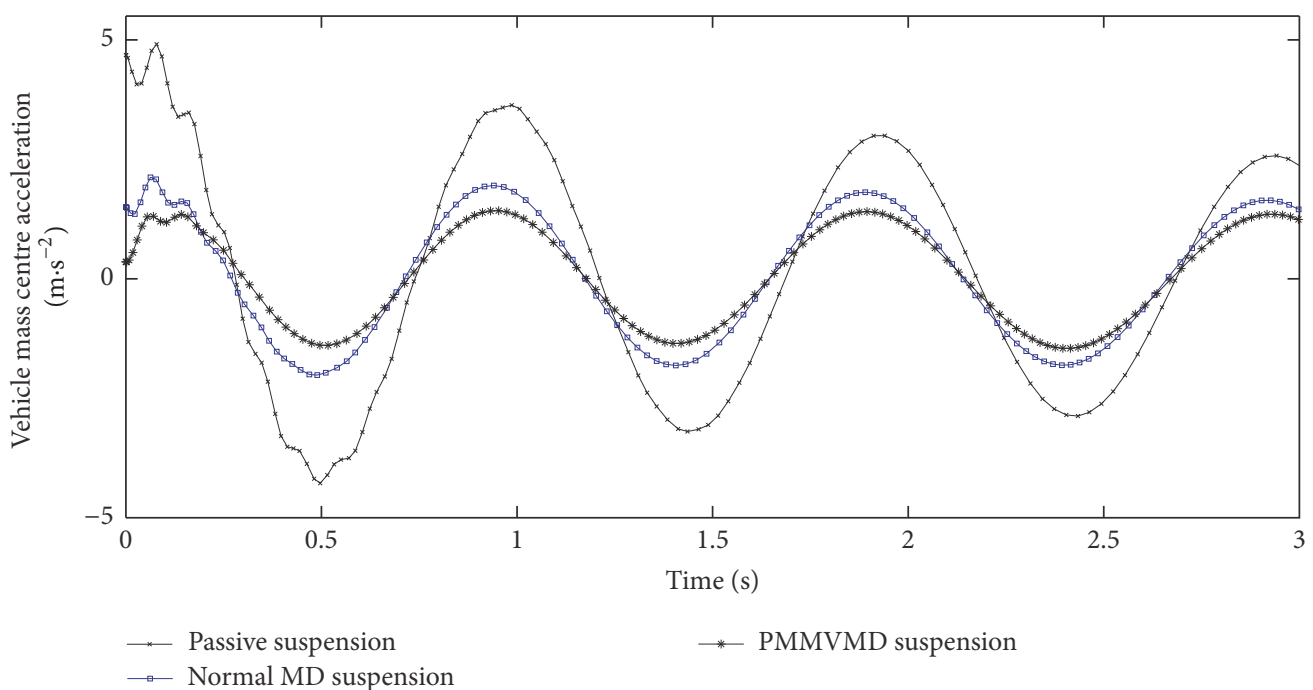

(a)

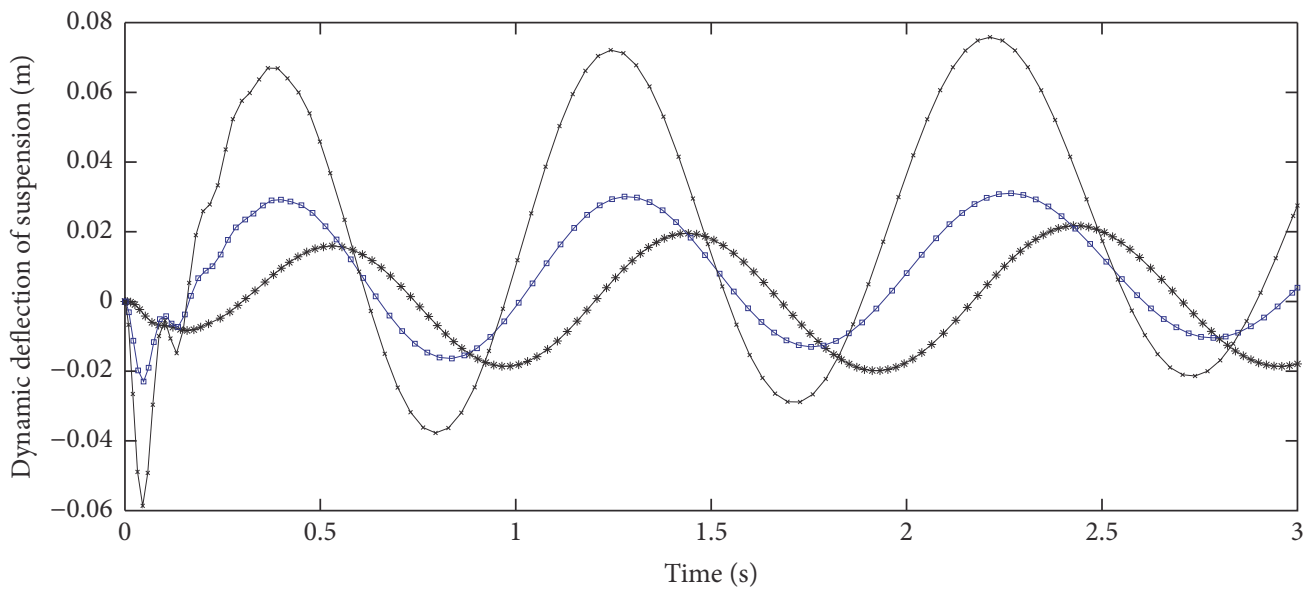

* PMMVMD suspension

$\longrightarrow$ Passive suspension

$\rightarrow$ Normal MD suspension

(b)

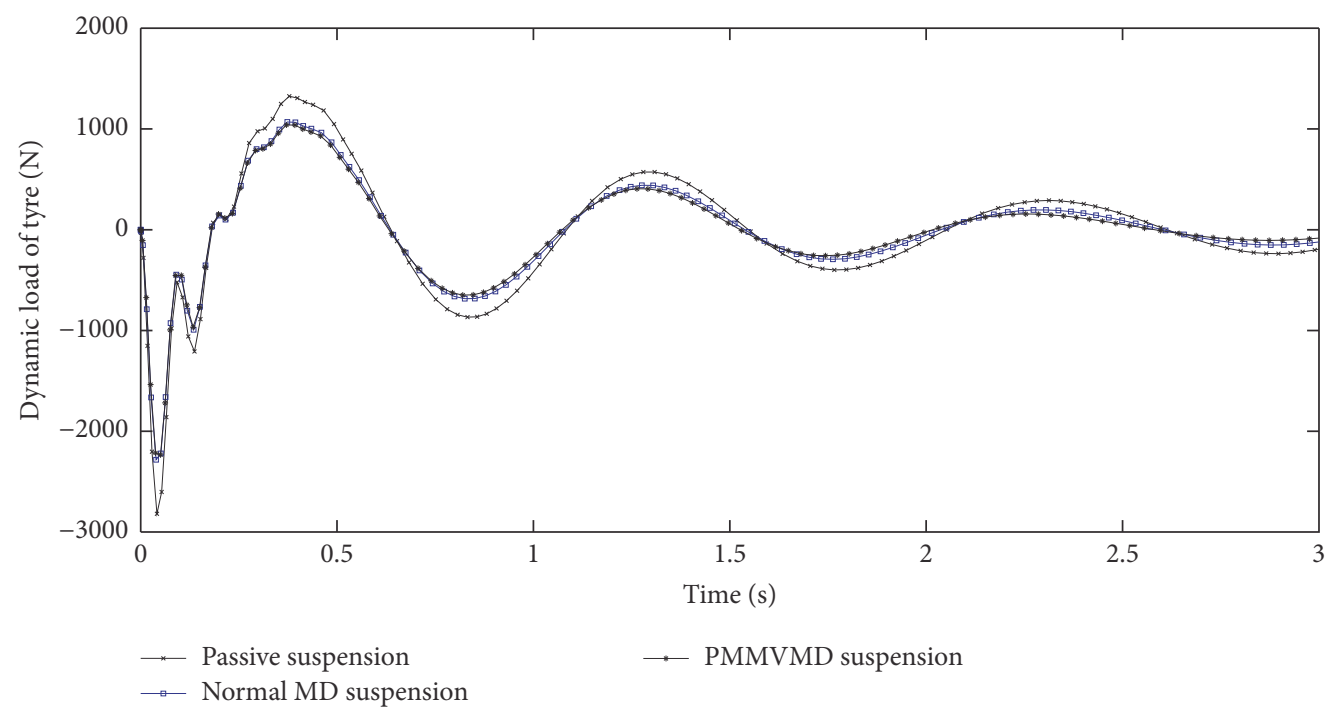

(c)

FIGURE 7: Results of simulation experiments with sine wave road surface input: (a) curve of VMCV acceleration; (b) curve of suspension dynamic deflection; (c) curve of tyre dynamic load. 


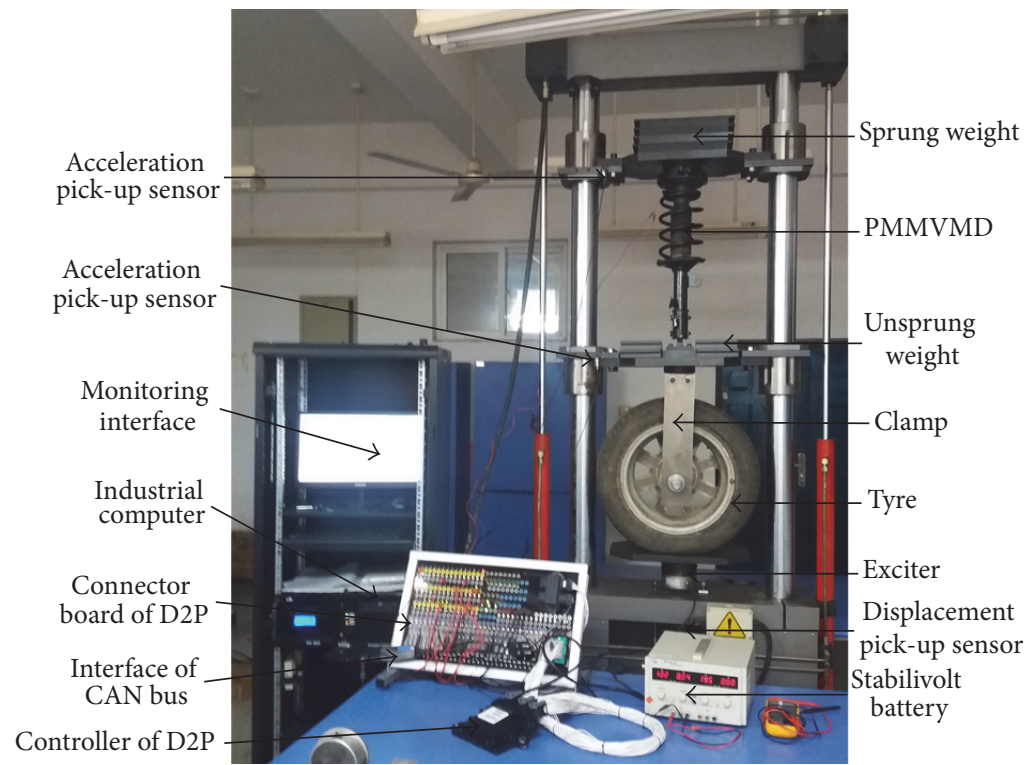

FIGURE 8: Quarter suspension testing system.

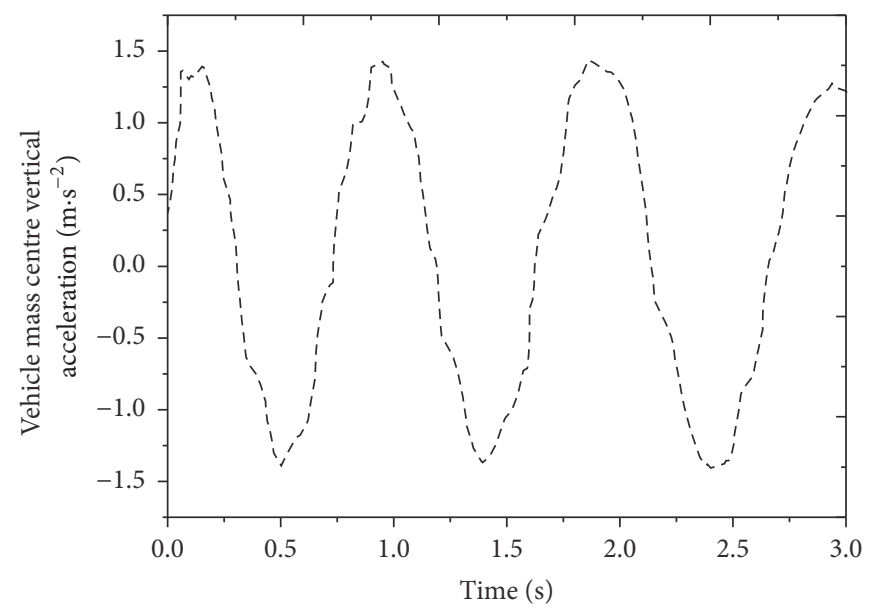

(a)

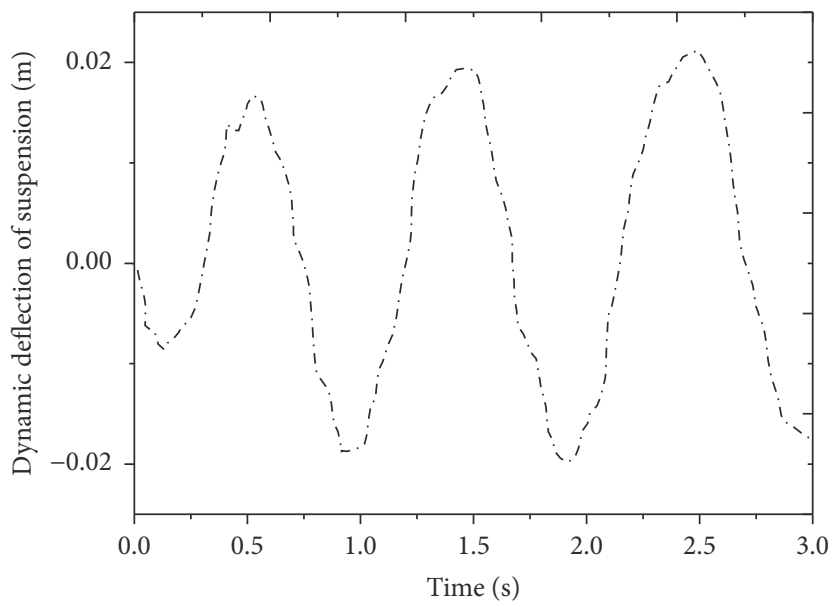

(b)

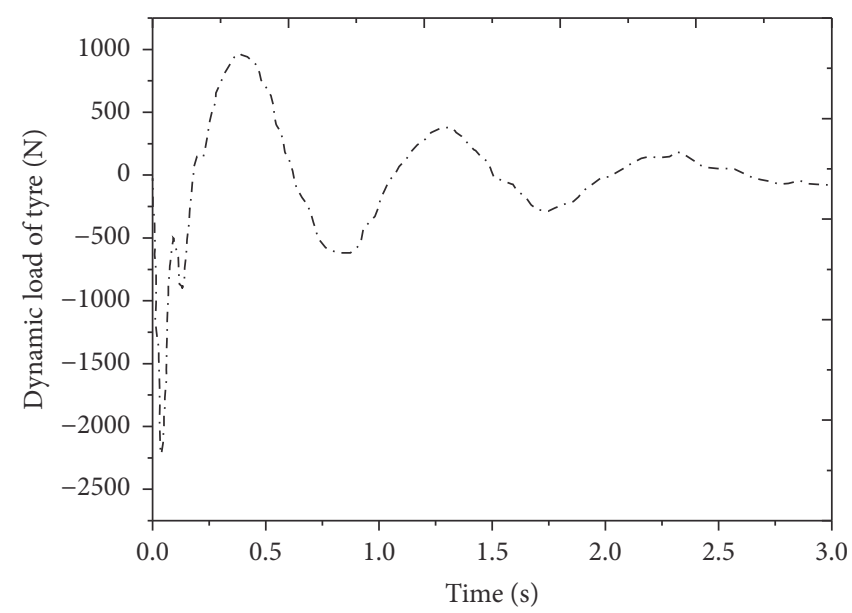

(c)

FiguRE 9: Results of bench tests with sine wave road surface input. (a) Curve of VMCV acceleration; (b) curve of suspension dynamic deflection; (c) curve of tyre dynamic load. 
is good. It also suggests that error between simulation results and bench test results is minor, which, in turn, proves that the working performance of PMMVMD suspension based on FOA-LQG algorithm is desirable.

\section{Conclusion}

In order to enhance suspension working performance, a novel MD with permanent magnet and magnetic valve is designed and the PMMVMD suspension is studied. The whole research work in this paper can be summarized as follows:

(1) A permanent magnet and magnetic valve are introduced to normal MD to make sure there is magnetic field in MD under both the PMMVMD's working and nonworking state. Thus, sedimentation of magnetorheological fluid can be avoided and PMMVMD can work more robustly. On the basis of analyzing the working principle of newly designed MD, the model of PMMVMD and quarter PMMVMD suspension is built.

(2) Homogeneous-distribution operation of fruit fly group and group-radius-decrease-with-increase-ofoptimization-generations operation are introduced to normal FOA. Meanwhile, optimizing steps of normal FOA are developed, so the optimizing speed and accuracy of the developed FOA are enhanced. Simulation experiments are conducted and the results indicate that optimizing effects of the developed FOA is good. On this basis, FOA-LQG control algorithm for PMMVMD suspension is designed.

(3) Two simulation experiments with B road surface input and sine wave road surface input are conducted. The simulation results indicate that the working performance of PMMVMD suspension is good and the control effect of FOA-LQG is good, too. The bench tests with sine wave road surface input are also carried out. The comparison of simulation results and bench test results suggests that the simulation results are right.

\section{Competing Interests}

The authors declare that they have no competing interests.

\section{Acknowledgments}

The authors would like to thank the financial support of the Natural Science Foundation of China (Grant no. 51175135, no. 51275002, and no. 51575001), of Anhui Provincial Education Department Natural Science Foundation (Grant no. KJ2014A282 and no. KJ2016A799), of open fund of Mechanics Key Laboratory of Anhui Polytechnic University (no. 201606), of the open fund of National Precision Engineering Technology Research Center of Small and Special Electric Machine (Grant no. 3651HT001), and of Natural
Science Foundation of Anhui Province of China (Grant no. 1708085ME127).

\section{References}

[1] O. Marinică, D. Susan-Resiga, F. Bălănean, D. Vizman, V. Socoliuc, and L. Vékás, "Nano-micro composite magnetic fluids: magnetic and magnetorheological evaluation for rotating seal and vibration damper applications," Journal of Magnetism and Magnetic Materials, vol. 406, pp. 134-143, 2016.

[2] S. K. Mangal and A. Kumar, "Experimental studies of in-house developed magnetorheological fluid in a damper," International Journal of Performability Engineering, vol. 11, no. 3, pp. 257-264, 2015.

[3] B. Minorowicz, F. Stefański, G. Pittner, and R. Regulski, "Share mode magnetorheological dampers for vibration attenuation in domestic washing machines," Advances in Intelligent Systems and Computing, vol. 350, pp. 147-156, 2016.

[4] Y.-J. Cha and A. K. Agrawal, "Robustness studies of sensor faults and noises for semi-active control strategies using large-scale magnetorheological dampers," Journal of Vibration and Control, vol. 22, no. 5, pp. 1228-1243, 2016.

[5] Y. Q. Ni, Z. H. Chen, and S. W. Or, "Experimental identification of a self-sensing magnetorheological damper using soft computing," Journal of Engineering Mechanics, vol. 141, no. 7, pp. 113, 2015.

[6] K. Shah, D. Xuan Phu, and S.-B. Choi, "Rheological properties of bi-dispersed magnetorheological fluids based on plate-like iron particles with application to a small-sized damper," Journal of Applied Physics, vol. 115, no. 20, Article ID 203907, 2014.

[7] N. Caterino, "Semi-active control of a wind turbine via magnetorheological dampers," Journal of Sound \& Vibration, vol. 345, pp. 1-17, 2015.

[8] R. Zalewski, J. Nachman, M. Shillor, and J. Bajkowski, "Dynamic model for a magnetorheological damper," Applied Mathematical Modelling, vol. 38, no. 9-10, pp. 2366-2376, 2014.

[9] I. I. M. Yazid, S. A. Mazlan, T. Kikuchi, H. Zamzuri, and F. Imaduddin, "Design of magnetorheological damper with a combination of shear and squeeze modes," Materials \& Design, vol. 54, pp. 87-95, 2014.

[10] J. W. Sohn, J.-S. Oh, and S.-B. Choi, "Design and novel type of a magnetorheological damper featuring piston bypass hole," Smart Materials \& Structures, vol. 24, no. 3, pp. 1-13, 2015.

[11] S. Sun, J. Yang, W. Li, H. Deng, H. Du, and G. Alici, "Development of a novel variable stiffness and damping magnetorheological fluid damper," Smart Materials and Structures, vol. 24, no. 8,2015 .

[12] M. Ito, S. Yoshida, H. Fujitani, and Y. Sato, "Earthquake response reduction of mid-story isolated system due to semiactive control using magnetorheological rotary inertia mass damper," Proceedings of the SPIE, vol. 9431, Article ID 943127, 9 pages, 2015.

[13] S. Yim and J. Jeong, "Design of an active suspension controller with simple vehicle models," Journal of Institute of Control, Robotics and Systems, vol. 22, no. 3, pp. 177-185, 2016.

[14] D. X. Phu, S.-B. Choi, Y.-S. Lee, and M.-S. Han, "Vibration control of a vehicle's seat suspension featuring a magnetorheological damper based on a new adaptive fuzzy slidingmode controller," Proceedings of the Institution of Mechanical Engineers, Part D: Journal of Automobile Engineering, vol. 230, no. 4, pp. 437-458, 2016. 
[15] H. D. Choi, C. K. Ahn, M. T. Lim, and M. K. Song, "Dynamic output-feedback $H_{\infty}$ control for active half-vehicle suspension systems with time-varying input delay," International Journal of Control, Automation and Systems, vol. 14, no. 1, pp. 59-68, 2016.

[16] A. Akbari and B. Lohmann, "Output feedback Ho/GH2 preview control of active vehicle suspensions: a comparison study of LQG preview," Vehicle System Dynamics, vol. 48, no. 12, pp. 1475-1494, 2010.

[17] S. Ding, X. Zhang, and J. Yu, “Twin support vector machines based on fruit fly optimization algorithm," International Journal of Machine Learning and Cybernetics, vol. 7, no. 2, pp. 193-203, 2016.

[18] S. M. Mousavi, N. Alikar, S. T. A. Niaki, and A. Bahreininejad, "Optimizing a location allocation-inventory problem in a twoechelon supply chain network: a modified fruit fly optimization algorithm," Computers and Industrial Engineering, vol. 87, pp. 543-560, 2015.

[19] M. Mitić, N. Vuković, M. Petrović, and Z. Miljković, "Chaotic fruit fly optimization algorithm," Knowledge-Based Systems, vol. 89, pp. 446-458, 2015.

[20] W.-T. Pan, "A new fruit fly optimization algorithm: taking the financial distress model as an example," Knowledge-Based Systems, vol. 26, pp. 69-74, 2012.

[21] L. D. Yépez, J. L. Carrillo, F. Donado, J. M. Sausedo-Solorio, and P. Miranda-Romagnoli, "Dynamical pattern formation in a lowconcentration magnetorheological fluid under two orthogonal sinusoidal fields," Journal of Magnetism and Magnetic Materials, vol. 408, pp. 321-329, 2016.

[22] S. Aguib, A. Nour, T. Djedid, G. Bossis, and N. Chikh, "Forced transverse vibration of composite sandwich beam with magnetorheological elastomer core," Journal of Mechanical Science and Technology, vol. 30, no. 1, pp. 15-24, 2016.

[23] M. Bocian, J. Kaleta, D. Lewandowski, and M. Przybylski, “Test setup for examination of magneto-mechanical properties of magnetorheological elastomers with use of a novel approach," Archives of Civil and Mechanical Engineering, vol. 16, no. 3, pp. 294-303, 2016.

[24] R. Russo, S. Strano, and M. Terzo, "Enhancement of vehicle dynamics via an innovative magnetorheological fluid limited slip differential," Mechanical Systems and Signal Processing, vol. 70-71, pp. 1193-1208, 2016.

[25] A. Benaglia, E. Auffray, P. Lecoq, H. Wenzel, and A. Para, "Space-time development of electromagnetic and hadronic showers and perspectives for novel calorimetric techniques," IEEE Transactions on Nuclear Science, vol. 63, no. 2, pp. 574579, 2016.

[26] S.-W. Cho, H.-J. Jung, and I.-W. Lee, "Smart passive system based on magnetorheological damper," Smart Materials and Structures, vol. 14, no. 4, pp. 707-714, 2005.

[27] T. Pranoto, K. Nagaya, Y. Ebara, and Q. Q. Long, "Vibration suppression device using permanent-electromagnet and MRF shear damper," Journal of Materials Processing Technology, vol. 181, no. 1-3, pp. 235-240, 2007.

[28] G. Song and M. Zeng, "A thin-film magnetorheological fluid damper/lock," Smart Materials \& Structures, vol. 14, no. 2, pp. 369-375, 2005.

[29] N. M. Ghazaly, A. E.-N. S. Ahmed, A. S. Ali, and G. T. A. ElJaber, "Ho control of active suspension system for a quarter car model," International Journal of Vehicle Structures and Systems, vol. 8, no. 1, pp. 35-40, 2016.

[30] M.-W. Li, J. Geng, D.-F. Han, and T.-J. Zheng, "Ship motion prediction using dynamic seasonal RvSVR with phase space reconstruction and the chaos adaptive efficient FOA," Neurocomputing, vol. 174, pp. 661-680, 2016.

[31] J.-Q. Zhao, K.-M. Li, B.-K. Chen, and Q.-S. Dai, "Slope stability evaluation based on FOA-GRNN algorithm," Electronic Journal of Geotechnical Engineering, vol. 19, pp. 6357-6369, 2014.

[32] L.-S. Wei, X. Wu, M.-Q. Niu, and Z.-Y. Chen, "FOA based PID controller for human balance keeping," Applied Mechanics and Materials, vol. 494-495, pp. 1072-1075, 2014.

[33] S. Yu, S. Yang, and S. Su, "Self-adaptive step firefly algorithm," Journal of Applied Mathematics, vol. 2013, Article ID 832718, 8 pages, 2013. 


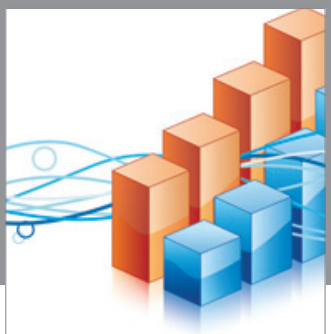

Advances in

Operations Research

vatem alat4

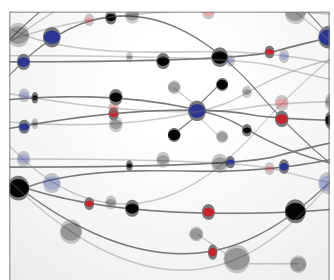

\section{The Scientific} World Journal
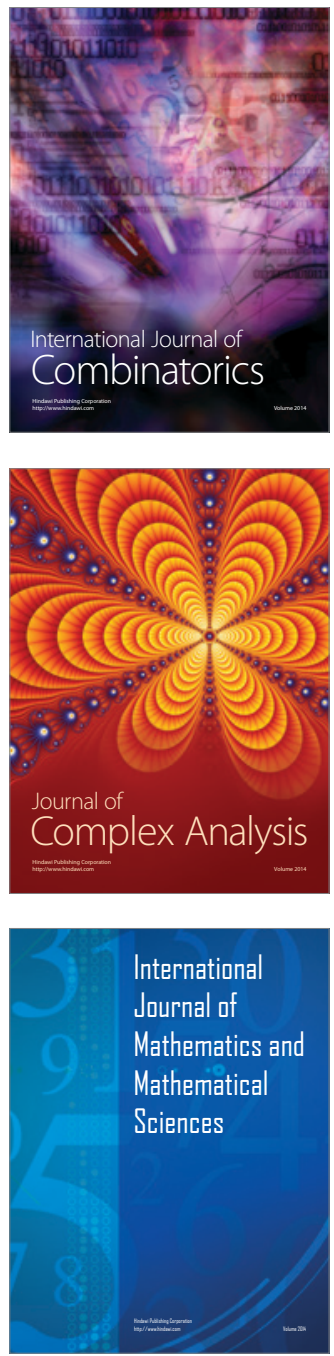
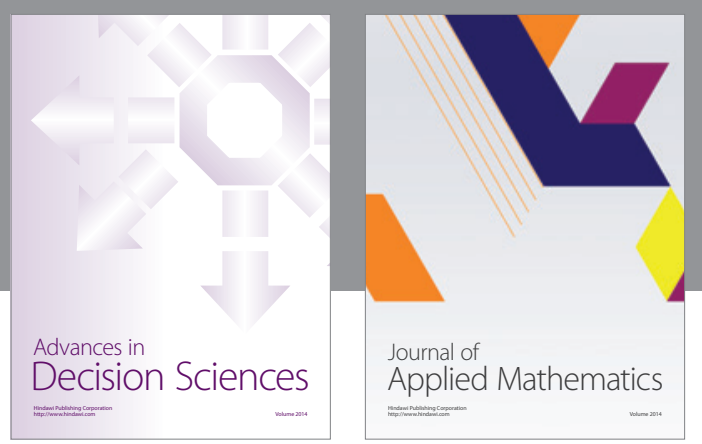

Algebra

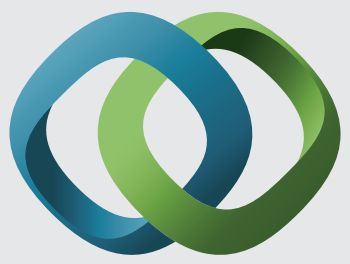

\section{Hindawi}

Submit your manuscripts at

https://www.hindawi.com
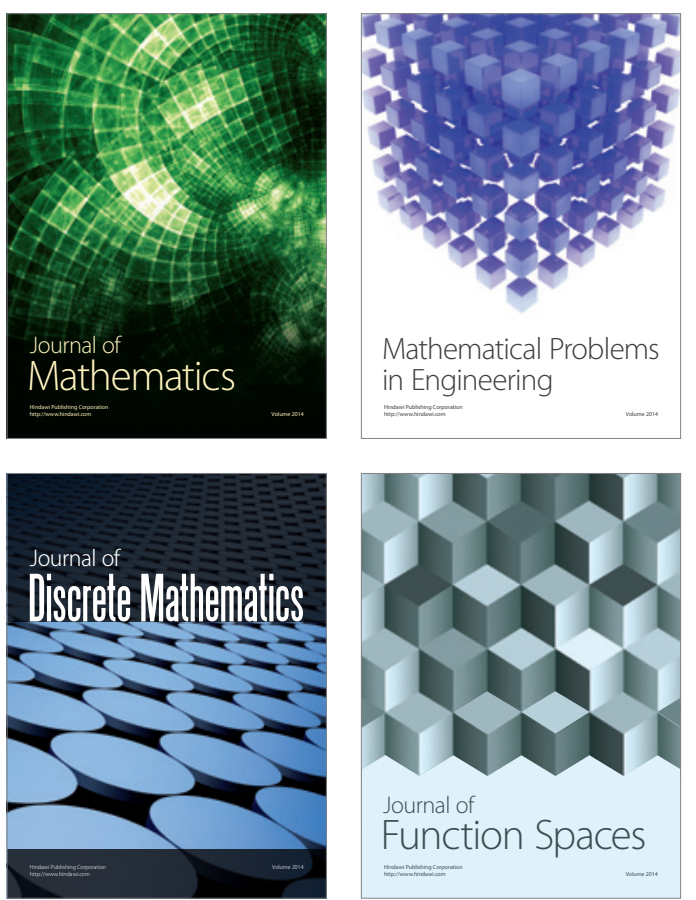

Mathematical Problems in Engineering
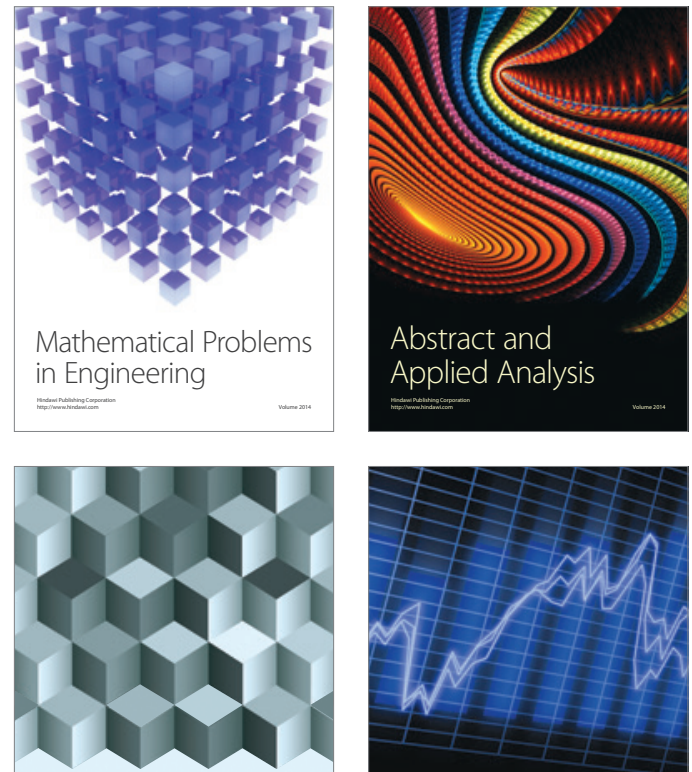

Journal of

Function Spaces

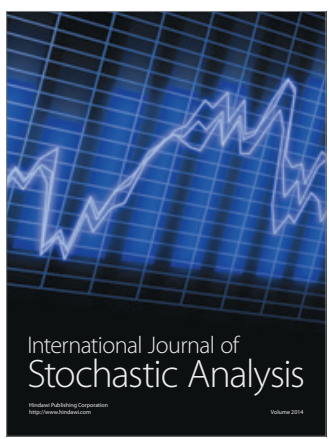

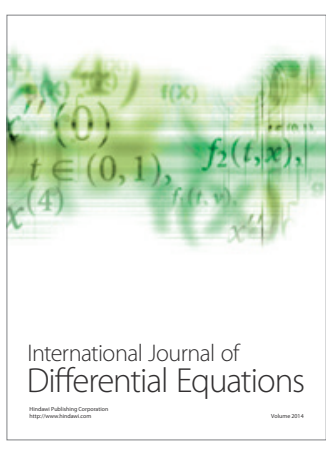
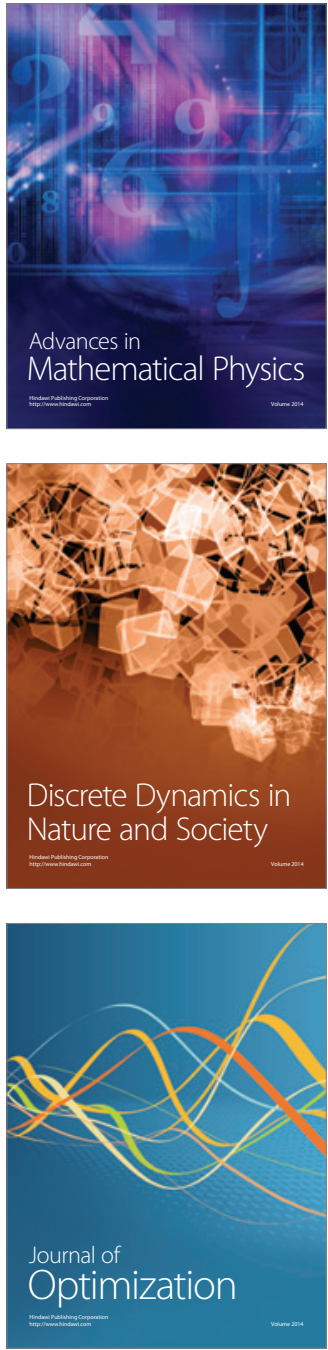